\title{
Duplication of the inferior vena cava: anatomy, embryology and classification proposal
}

\author{
Konstantinos Natsis $\cdot$ Stylianos Apostolidis · \\ George Noussios · Efthymia Papathanasiou • \\ Aggela Kyriazidou • Vasilios Vyzas
}

Received: 11 September 2008/ Accepted: 3 February 2009/Published online: 28 March 2009

(C) Japanese Association of Anatomists 2009

\begin{abstract}
A case of a duplicated inferior vena cava (IVC) along with other anatomical vessel variations in a 72-yearold male cadaver is presented. The anomalous vessels involved, besides the IVC, were the left testicular vein and artery, the left suprarenal artery and a superior accessory left renal artery. Based on the gross appearance of the preaortic anastomotic trunk between the left and right IVC as well as on the underlying embryological features, a classification is proposed: incomplete bilateral duplication of the IVC and complete bilateral duplication of the IVC. The latter can be further divided into three types: major, minor and asymmetric.
\end{abstract}

Keywords Anatomical variation .

Duplicated inferior vena cava $\cdot$ Renal vein .

Testicular vein $\cdot$ Vessel anomalies

\section{Introduction}

The duplicated inferior vena cava (IVC) is a well-recognized entity and has been found quite frequently on a clinical base (Evans et al. 2001; Shaw et al. 2003; Nirupama et al. 2005). Among the anatomic studies (Senecail et al. 1987; Khaledpour et al. 1990; Itoh et al. 2001; Sórócó et al. 2001; Xue et al. 2006) that fully describe this anatomic variation, there is a basic difference at the drainage point of the rudimentary left IVC to the right IVC. The way

\footnotetext{
K. Natsis $(\bowtie) \cdot$ S. Apostolidis · G. Noussios ·

E. Papathanasiou · A. Kyriazidou · V. Vyzas

Department of Anatomy, Medical School,

Aristotle University of Thessaloniki,

P.O. Box 300, 54124 Thessaloniki, Greece

e-mail: natsis@med.auth.gr
}

these two vessels anastomose designates the type of duplication, and this has not been discussed in detail previously.

Herein we present a case of a duplicated IVC and other vessel anomalies in the retroperitoneum region in a male cadaver. In addition to the anatomic description, a classification is proposed, and the underlying embryology is pinpointed.

\section{Case report}

The anomaly was found during a routine anatomy dissection in a cadaver of a 72-year-old man who died of respiratory complications because of metastatic prostate cancer. The two common iliac veins did not join at the level of the L4 vertebra to form the IVC, but ran bilaterally towards the abdominal aorta and ended at the level of the L1 vertebra. Specifically, the left common iliac vein formed at the level of the L5 vertebra from the junction of the left internal and external iliac veins. Then it ascended, representing the left IVC, along the left side of the abdominal aorta where at the level of the L2 vertebra it crossed over the abdominal aorta, and at the level of the L1 vertebra it connected with the right IVC. At the same level, the right renal vein drained into the right IVC. The two branches of the IVC and also the arched part of the left IVC had approximately the same caliber. Specifically, the diameters of the left and right IVC were 19.5 and $20 \mathrm{~mm}$, respectively, whereas the preaortic trunk was $21 \mathrm{~mm}$ in diameter. At the level of the L2 vertebra, the left renal vein drained at a right angle into the left IVC. The left suprarenal vein did not drain into the left renal vein, but into the arched part of the left IVC (Fig. 1). The left testicular vein was an incomplete 


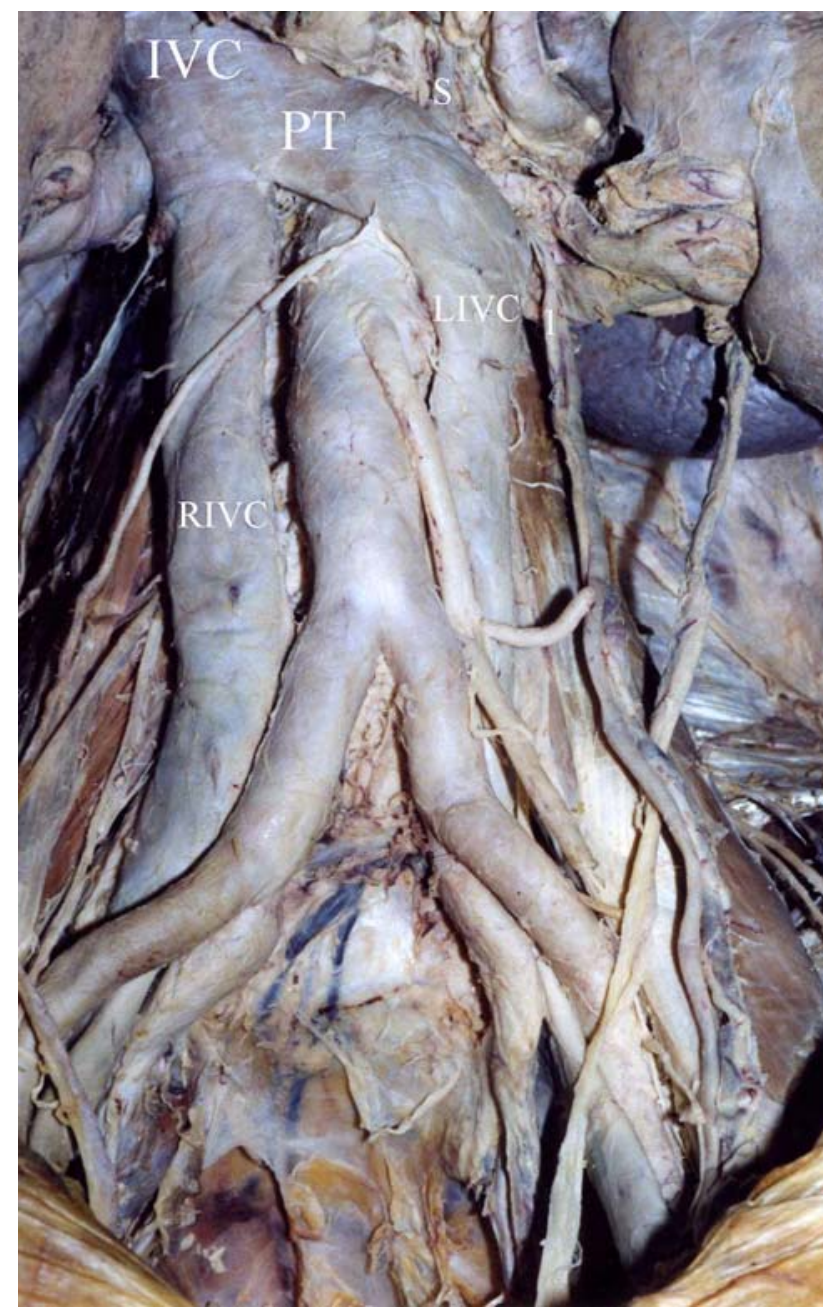

Fig. 1 Gross appearance of the duplicated inferior vena cava and the associated vessel anomalies. IVC inferior vena cava, $P T$ preaortic trunk, LIVC left inferior vena cava, RIVC right inferior vena cava, $S$ suprarenal vein, $l$ left testicular artery

duplicated vein that consisted of medial and lateral trunks. The two venous trunks left the internal inguinal ring and ran upwards where approximately at the midpoint of their course they connected to a common trunk, which opened normally into the left renal vein.

At the left side the renal artery was normal, but there was also a superior accessory renal artery that originated from the abdominal aorta, above the left renal artery. The superior accessory renal artery coursed obliquely and terminated at the renal hilum in front of the left renal vein. The left testicular artery originated from the abdominal aorta just above the renal artery and passed in front of the renal vein (Fig. 2). The origin, the course and the territories of the other vessels were according to the normal pattern. The kidneys and the ureters were also normal.

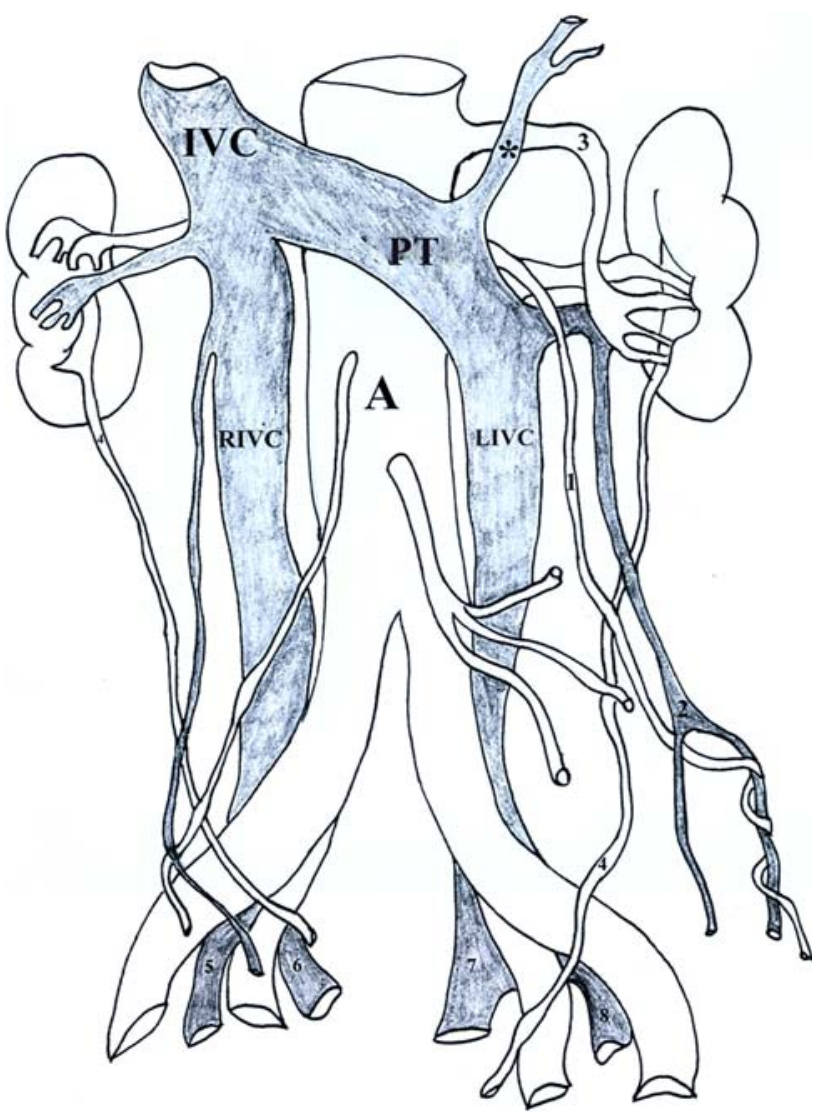

Fig. 2 Schematic depiction of the vessel anomalies. IVC inferior vena cava, RIVC right inferior vena cava, LIVC left inferior vena cava, $P T$ preaortic trunk, *suprarenal vein, 1 left testicular artery, 2 left testicular vein, 3 accessory renal artery, 4 ureters, 5 right external iliac vein, 6 right internal iliac vein, 7 left internal iliac vein, 8 left external iliac vein

\section{Discussion}

A general classification of the IVC anomalies comprises the transposition of the IVC with (Taniguchi et al. 2001; Honma et al. 2008) or without (Babaian and Johnson 1979) regressed right IVC, ipsilateral duplication of the IVC (Doyle et al. 1992; Tagliafico et al. 2007), bilateral duplication of the IVC and extremely rare variations, such as the marsupial vena cava (Natsis et al. 2003). The duplication of the IVC is the most common of all the anomalies of the IVC with a rate of incidence of $0.2-3 \%$ (Bass et al. 2000).

In our case we observed that the left IVC did not drain into the left renal vein, but after receiving the left renal vein it continued with a major preaortic trunk that traveled obliquely and emptied into the right IVC. We reviewed only anatomic case reports and compared them with our case in order to designate the gross appearance of the preaortic trunk. In contrast to the typical case of infrarenal duplication (Khaledpour et al. 1990) where the left IVC is quite smaller than the right IVC and empties into the left 
renal vein, there were several cases that involved the preaortic trunk. Therefore, we defined our case as complete bilateral duplication of the IVC because it comprised both the renal and the infrarenal segment of the IVC. We further classified the complete bilateral duplication according to the review of the literature (Waterston 1913; Rischbieth 1914; Senecail et al. 1987; Lewis 1992; Wagner and Bogush 1993; Itoh et al. 2001; Sórócó et al. 2001; Tohno et al. 2006; Xue et al. 2006) into three types (Fig. 3). Type I or major duplication, as in our case, comprises two bilaterally symmetrical and approximately of the same caliber trunks and a preaortic trunk of the same calider. In this type, the left and the right IVCs are just near the lateral border of the aorta (Senecail et al. 1987; Wagner and Bogush 1993). Type II or minor type comprises two bilaterally symmetrical and approximately of the same caliber trunks, but is smaller in comparison to the preaortic trunk. In this type the prominent venous trunk is the preaortic trunk (Waterston 1913; Rischbieth 1914; Tohno et al. 2006; Xue et al. 2006). Type III or asymmetric type comprises small left IVC, larger right IVC and even larger preaortic trunk or small left IVC, larger preaortic trunk and even larger right IVC. In this type the prominent vessel is either the right IVC or the preaortic trunk (Senecail et al. 1987; Lewis 1992; Itoh et al. 2001; Sórócó et al. 2001). In the two latter types, the left and right IVCs may have enough distance from the lateral border of the aorta. It is therefore obvious that IVC duplication should be defined not only with regard to the size of the right and left IVC, but basically it should be based on the presence of the preaortic trunk.

As far as the embryology of the IVC is concerned, there are two prominent theories about the IVC formation. The first theory is the most common, and Nomina Embryologica (1983) is based upon this theory (Cornillie and Simoens 2005). According to this theory, there are three paired embryonic veins with several anastomoses among them that regress and form the IVC. Namely, the posterior cardinal veins, the subcardinal veins and the supracardinal veins. Caval development begins in the 6th week of fetal life and progresses rapidly, with formation of all three precursor venous systems by the 8th week (Mathews et al. 1999).

The renal segment of the IVC develops from the right suprasubcardinal and postsubcardinal anastomoses, and the infrarenal segment develops from the right supracardinal vein. Persistence of both supracardinal veins results in duplication of the IVC (Bass et al. 2000), although failure to form an adequate anastomosis between the embryonic veins has also been suggested as a potent explanation (Shaw et al. 2003).

Based on the gross appearance of the three types we described, it seems that although failure of regression of the left IVC can result in the incomplete duplication of the IVC, in our case the etiologic factor is probably more complex. We assume that the complete bilateral duplication results from persistence of the left suprasubcardinal and postsubcardinal anastomoses and probably of the intersubcardinal anastomosis, which in turn results in persistence of the left supracardinal vein. Especially in types I and II, the left IVC shows no signs of regression at an early embryological stage in contrast to the incomplete bilateral duplication where the small size of the left IVC and the normal left renal vein could be attributed to inadequate obstruction of the vessel, which results in persistence of the aberrant vessel.

The basic difference in the second theory, the sacrocardinal theory, is that the basic role of the supracardinal veins is constricted to the formation of the azygos and hemiazygos veins, whereas the formation of the IVC is attributed to a new pair of veins that are the last to appear, and they are called sacrocardinal veins (Cornillie and Simoens 2005). Both theories have similarities and
Fig. 3 Schematic drawings of the three types of IVC duplication
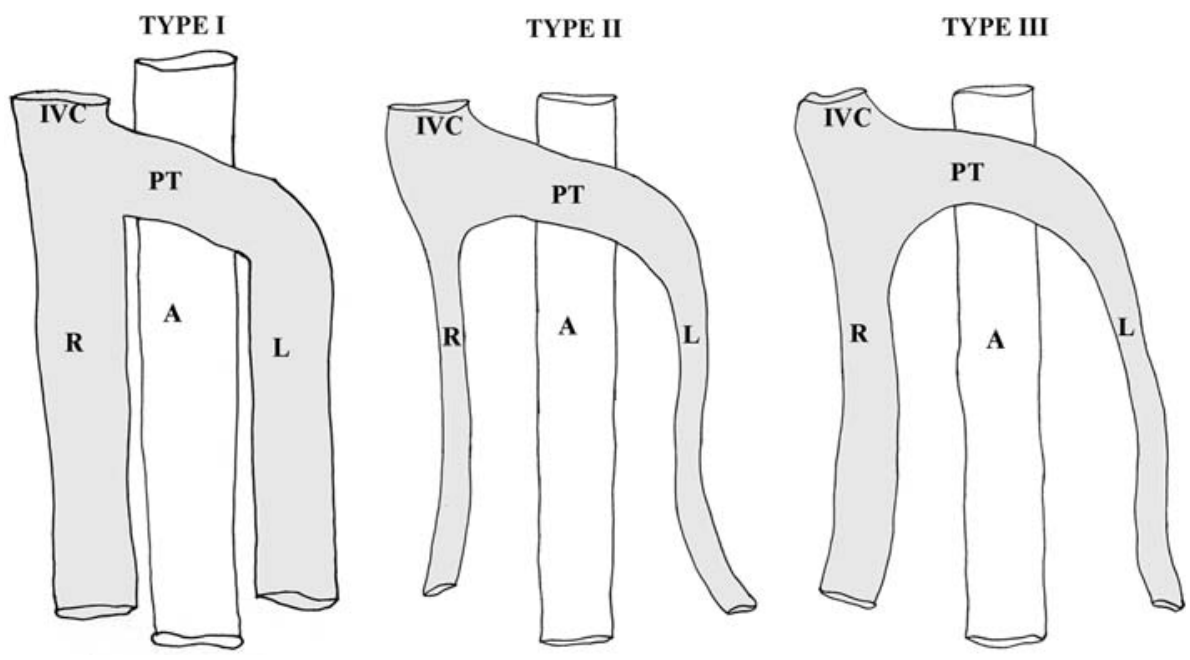
differences, and we intend neither to verify nor to reject any of them. Since the development of the IVC still remains somehow unclear, more emphasis should be placed on the anastomoses that develop among the embryonic veins.

In our case the left and right renal veins were according to the normal pattern. Multiple renal veins are common on the right side (up to $15 \%$ ), and anomalies of the left side comprise the retroaortic left renal vein and the circumaortic left renal vein with an incidence of 1.2-3.3 and 1.5-8.7\%, respectively (Kudo et al. 2003). The circumaortic left renal collar can be divided into three different morphological types (Natsis et al. 2008), and this indicates the complexity of the underlying embryological development, but also the role the anastomoses play on the different morphological patterns. Multiple renal veins are more frequent on the right side presumably due to the fact that the postsubcardinal anastomosis does not regress, but participates in the formation of the renal segment of the IVC. As a consequence the dorsal renal vein may persist, as well. On the contrary, the postsubcardinal anastomosis regresses on the left side and facilitates the regression of the left dorsal renal vein.

Anatomical variations of the testicular veins have been reported in the literature (Tubbs et al. 2005; Xue et al. 2005; Yang et al. 2008). Asala et al. (2001) documented in their study that the anatomical pattern of the testicular veins deviated from the normal one in $21.3 \%$ of specimens. These anatomical variations were mainly duplications, and they were more common on the left side. Furthermore, the incomplete duplicated testicular vein was found only on the left side. In our case the left testicular vein emptied into the left renal vein according to the normal pattern despite the persistence of the left supracardinal vein. We speculate that the incomplete duplicity is probably due to persistence of a posterior postsubcardinal anastomosis.

Normally, the left suprarenal vein enters the left renal vein. In their study Monkhouse and Khalique (1986) report that the left suprarenal vein entered the left renal vein medial to the entry of the left gonadal vein in all the 57 specimens, except from one case where the left suprarenal vein emptied into the left of the aorta. The left suprarenal vein in our case did not drain into the left renal vein, but it drained into the preaortic trunk. The left suprarenal vein develops from the embryonic cranial subcardinal vein, which empties into the intersubcardinal anastomosis (McClure and Butler 1925). Since the preaortic trunk is a combined trunk and comprises the intersubcardinal anastomosis, the drainage point of the left suprarenal vein is rather to be expected.

Anatomical variations of the renal arteries are quite common. Satyapal et al. (2001) report in their study that the incidence of a single additional renal artery is $23.2 \%$ and that it is more common on the left side $(27.6 \%)$ and in males $(33.1 \%)$. Nevertheless, renal artery variations show ethnic and racial differences, so the incidence may vary among different populations (Özkan et al. 2006). Renal arteries are derived from the embryonic mesonephric arteries. Regression of these arteries results in persistence of a single mesonephric artery and formation of a single renal artery. Dysplasia of the mesonephric arteries results in multiple renal arteries (Özkan et al. 2006).

Anatomical variations with regard to the number, course and origin of the testicular arteries have been reported in the literature (Notkovich 1956; Çiçekcibaşi et al. 2002; Naito et al. 2006). Notkovich (1956) classified the gonadal artery variations in three types based on their origin and course in relation to the renal pedicle. Our case was classified as type II according to Notkovich's (1956) classification, who also reported that type II was found in $13.1 \%$ of cases on the left side. The gonadal arteries arise from the caudal lateral mesonephric arteries, but the high positioned arteries seem to originate from the cranial group of the lateral mesonephric arteries (Çiçekcibaşi et al. 2002).

There are several classifications of the IVC anatomical variations. Mathews et al. (1999) classify the anomalies of the IVC according to the anomalies of the corresponding embryonic veins, but in the anomalies of the renal segment, the complete bilateral duplication is not included. Ueda et al. (1983) in an attempt to determine the incidence of the IVC anomalies observed by CT divided the double IVC anomalies only with regard to the size of the left and right IVCs. Morita et al. (2007) classified pelvic venous variations in cases of congenital venous anomalies and in cases of double IVC estimated only the diameter of the left and right IVCs. Only the measurement of the size of the left and right IVCs is not enough to determine the type of duplication.

Although there are various classifications about the duplicated vena cava, no one differentiates the complete from the incomplete duplication. Especially, classifications with regard to accompanied vessel anomalies should distinguish at least the complete from the incomplete bilateral duplication of the IVC. Embryogenesis is not a random procedure, and since the embryonic veins develop symmetrically, each type of duplication may be associated with specific venous anomalies.

The duplicated vena cava along with other vessel anomalies in the retroperitoneum can lead both to misdiagnosis and to surgical complications. Surgeons, radiologists, oncologists and urologists who have to cope with the retroperitoneum region should not only have a thorough knowledge of the normal anatomy of this region, but also they should be familiarized with the potent anatomical variations and with the exact type of each variation as well. 


\section{References}

Asala S, Chaudhary SC, Masumbuko-Kahamba N, Bidmos M (2001) Anatomical variations in the human testicular blood vessels. Ann Anat 183:545-549

Babaian RJ, Johnson DE (1979) Major venous anomalies complicating retroperitoneal surgery. South Med J 72:1254-1258

Bass JE, Redwine MD, Kramer LA, Huynh PT, Harris JH Jr (2000) Spectrum of congenital anomalies of the inferior vena cava: cross sectional imaging findings. Radiographics 20:639-652

Çiçekcibaşi AE, Salbacak A, Şeker M, Ziylan T, Büyükmumcu M, Uysal III (2002) The origin of gonadal arteries in human fetuses: anatomical variations. Ann Anat 184:275-279

Cornillie P, Simoens P (2005) Prenatal development of the caudal vena cava in mammals: review of the different theories with special reference to the dog. Anat Histol Embryol 34:364-372

Doyle AJ, Melendez MG, Simons MA (1992) Ipsilateral duplication of the inferior vena cava. J Clin Ultrasound 20:481-485

Evans JC, Earis J, Curtis J (2001) Thrombosed double inferior vena cava mimicking paraaortic lymphadenopathy. $\mathrm{Br} \mathrm{J}$ Radiol 74:192-194

Honma S, Tokiyoshi A, Kawai K, Koizumi M, Kodama K (2008) Left inferior vena cava with regressed right inferior vena cava. Anat Sci Int 83:173-178

Itoh M, Moriyama H, Tokunaga $\mathrm{Y}$ et al (2001) Embryological consideration of drainage of the left testicular vein into the ipsilateral renal vein: analysis of cases of a double inferior vena cava. Int J Androl 24:142-152

Khaledpour C, Matanovic P, Rienäcker J, Grönniger J (1990) An abdominal aortic aneurysm in combination with duplication of the inferior vena cava, the right renal artery and the right renal vein. Surg Radiol Anat 12:73-76

Kudo FA, Nishibe T, Miyazaki K, Flores J, Yasuda K (2003) Left renal vein anomaly associated with abdominal aortic aneurysm surgery: report of a case. Surg Today 33:609-611

Lewis SJ (1992) Observations on a double inferior vena cava. A case report with a literature review. Clin Anat 5:227-233

Mathews R, Smith PA, Fishman EK, Marshall FF (1999) Anomalies of the inferior vena cava and renal veins: embryologic and surgical considerations. Urol 53:873-880

McClure CFW, Butler EG (1925) The development of the vena cava inferior in man. Am J Anat 35:331-383

Monkhouse WS, Khalique A (1986) The adrenal and renal veins of man and their connections with azygos and lumbar veins. J Anat 146:105-115

Morita S, Higuchi M, Saito N, Mitsuhashi N (2007) Pelvic venous variations in patients with congenital inferior vena cava anomalies: classification with computed tomography. Acta Radiol 48:974-979

Naito M, Terayama H, Nakamura Y, Hayashi S, Miyaki T, Itoh M (2006) Left testicular artery arching over the ipsilateral renal vein. Asian J Androl 8:107-110

Natsis K, Iordache G, Xepoulias P, Tsikaras P (2003) Preaortic iliac venous confluence. Marsupial vena cava. Case report. Morphologie 87:21-23

Natsis K, Tsitouridis I, Totlis T, Levva S, Tsikaras P, Skandalakis P (2008) Proposal for classification of the circumaortic renal collar's morphology. Am Surg 74:1190-1194
Nirupama A, Pallapothu R, Holmes R, Johnson MD (2005) Inferior vena cava duplication and deep venous thrombosis: case report and review of literature. Ann Vasc Surg 19:740-743

Nomina Embryologica (1983) In: Nomina anatomica, 5th edn; Nomina Histologica, 2nd edn and Nomina Embryologica, 2nd edn. Prepared by Subcommittees of the International Anatomical Nomenclature Committee. Williams \& Wilkins, Baltimore, p 1E22

Notkovich H (1956) Variations in the testicular and ovarian arteries in relation to renal pedicle. Surg Gynecol Obstet 103:487-495

Özkan U, Oğuzkurt L, Tercan F, Kizilkiliç O, Koç Z, Koca N (2006) Renal artery origins and variations: angiographic evaluation of 855 consecutive patients. Diagn Interv Radiol 12:183-186

Rischbieth H (1914) Anomaly of the inferior vena cava: duplication of the post-renal segment. J Anat Physiol 48:287-292

Satyapal KS, Haffejee AA, Singh B, Ramsaroop L, Robbs JV, Kalideen JM (2001) Additional renal arteries incidence and morphometry. Surg Radiol Anat 23:33-38

Senecail B, Lefevre C, Person H, Meriot P (1987) Radiologic anatomy of duplication of the inferior vena cava: a trap in abdominal imaging. A report of 8 cases. Surg Radiol Anat 9:151-157

Shaw MBK, Cutress M, Papavassiliou V, White S, Thompson M, Sayers R (2003) Duplicated inferior vena cava and crossed renal ectopia with abdominal aortic aneurysm: preoperative anatomic studies facilitate surgery. Clin Anat 16:355-357

Sórócó HS, Erbil KM, Tastan H, Yener N (2001) Anomalous veins of the retroperitoneum: clinical considerations. Surg Radiol Anat 23:443-445

Tagliafico A, Capaccio E, Rosenberg I, Martinoli C, Derchi LE (2007) Double right inferior vena cava associated with an anomalous venous ring encircling the right common iliac artery: report of one case with CT and US. Eur J Radiol Extra 64:111115

Taniguchi H, Miyauchi Y, Kobayashi Y, Seino Y, Takano T (2001) Case report: pulmonary embolism from thrombosis in a duplicated inferior vena cava developing after an electrophysiologic procedure. J Interv Card Electrophysiol 5:75-79

Tohno Y, Tohno S, Azuma C et al (2006) One case of the double inferior venae cavae found in a Japanese man. J Nara Med Assoc 57:193-197

Tubbs RS, Salter EG, Oakes WJ (2005) Unusual drainage of the testicular veins. Clin Anat 18:536-539

Ueda J, Hara K, Kobayashi Y, Ohue S, Uchida H (1983) Anomaly of the inferior vena cava observed by CT. Comput Radiol 7:145-154

Wagner J, Bogush G (1993) An abnormal pattern of blood vessels in the retroperitoneal space with a duplicated inferior vena cava in an adult: a case report. Surg Radiol Anat 15:201-205

Waterston D (1913) Duplication of the post-renal segment of the vena cava inferior. J Anat Physiol 47:433-435

Xue HG, Yang CY, Ishida S et al (2005) Duplicate testicular veins accompanied by anomalies of the testicular arteries. Ann Anat 187:393-398

Xue HG, Yang CY, Asakawa M, Tanuma K, Ozawa H (2006) Duplication of the inferior vena cava associated with other variations. Anat Sci Int 82:121-125

Yang CY, Xue HG, Tanuma K, Ozawa H (2008) Variations of the bilateral testicular veins: embryological and clinical considerations. Surg Radiol Anat 30:53-55 